of ofloxacin: adverse drug reactions reported during phase-II studies in Europe and Japan. Infection, 14 (Sup-1. 4), 332-334.

Cohen, A. J., Ren, M. F. \& Noble, R. C. (1984) A comparison of rosoxacin with ampicilin and probenecid in the treatment of uncomplicated gonorrhea. Journal of Sexually Transmitted Diseases, 11, 24-28.

Gleckman, R., Alvarez, S., Joutert, D. W. \& Matthews, S. J. (1979) Drug therapy reviews: oxolinic acid. American Journal of Hospital Pharmacology, 36, 1077-1079.

\section{Oxymethalone and Aggression}

SIR: An 18 year-old male, treated with oxymethalone for idiopathic aplastic anaemia, developed a temporary increase in aggression. I believe this to be the first report of such an association with anabolic steroids prescribed for therapeutic reasons and there have been no reports to the Committee on Safety of Medicines of similar cases. However, hypomania (Freinhar \& Alvarez, 1985) and depression (Sheffer et al, 1979) have been described as a result of this class of drug. The use of anabolic steroids in sport has led to reports of increased aggression (Strauss et al, 1984). Doses, however, were idiosyncratic, excessive, not medically indicated, and often involved illicit drugs which purported to contain mixtures of somatotropin, a substance called "rhesus growth factor", and various anabolic steroids. They were usually taken in large quantities, far exceeding manufacturers' recommended therapeutic ranges. Overall, $35-80 \%$ of users reported an increase in aggression; of these, $75 \%$ found this to be a desirable effect.

Case Report: Within three weeks of commencing treatment with oxymethalone ( $150 \mathrm{mg}$ daily), the patient had broken the nose of an acquaintance, smashed two expensive guitars and considerably strained the patience of his girlfriend. He was an intelligent, insightful young man, weighing $70 \mathrm{~kg}$, who was studying for his ' $A$ ' levels, and who had every chance of gaining a place at university. He stated that his temper just 'snapped' following little or no provocation. Previously he had been a placid individual, and reports from his college tutor bore this out.

He was referred to psychiatric services after he had visited his GP, as he was worried either that his parents would eject him from the family home, or that he would end up in serious legal trouble, as a consequence of his actions. He was a modest drinker of alcohol (one pint of beer per week), and denied any other drug usage. His hobbies were unremarkable, and included listening to "heavy metal" music, of a variety which explored a rich seam of mysticism. He espoused philosophical ideals of peace and harmony. Exploration of his attitudes to his physical condition (which was responding well to treatment) revealed no major difficulties. There was similarly no evidence to suggest prior familial or other areas of interpersonal conflict. Previous medical history was unremarkable; there was no history of head injury. There was no family history of aggression or epilepsy. Mental state examination revealed no major abnormality other than the presenting complaint as described. Overall, he was an extremely pleasant young man.

The patient's haematologist confirmed that increased aggression had been reported within weeks of commencement of treatment. It was also felt that it was essential to continue the therapy for the next few months, depending on the haematological response.

In view of this, a cognitive/behavioural treatment plan was commenced. Within a fortnight, aggressive thoughts had diminished considerably, with only three being recorded, and no violent action had been taken on any of them. Pre-treatment levels were considerably higher than this, with daily aggressive thoughts, and perhaps weekly aggressive, remorse-inducing deeds having been reported. One month after starting this management the dose of oxymethalone was reduced by one-third.

This case indicates that in therapeutic doses anabolic steroids may induce aggression. It also shows that cognitive/behavioural techniques can serve to modify such anger and aggression. Finally, given the widely-reported illicit, uncontrolled usage of such substances by athletes and body-builders, the forensic implications of these observations may be considerable.

I am grateful to Dr Alan King for permission to report this case.

\section{Leicester General Hospital \\ Gwendolen Road \\ Leicester LES 4PW}

\section{References}

Freinhar, J. P. \& AlVAREz, W. (1985) Journal of Clinical Psychiatry. 46, 354-355.

HaUpT, H. A. \& Rovere, G. D. (1984) Anabolic steroids: a review of the biterature. The American Journal of Sports Medicine, 12, $469-483$.

Shepfer, A. L., Fearon, D. T. \& Austen, K. F. (1979) Clinical and biochemical effects of impeded androgen (oxymethalone) therapy of hereditary angiodema. Joumal of Allergy and Clinical Immunology. 64, 275-280.

Strauss, R. H., Ligett, M. T. \& LANEse, R. R. (1985) Anabolic steroid use and perceived effects in ten weight-trained athletes. Journal of the American Medical Association, 253, 2871-2873.

\section{CORRIGENDA}

Journal, June 1987, 150, 737-751 (C. V. R. Blacker \& A. W. Clare). The penultimate sentence in the first column of page 747 should read as follows: (In addition, the reported gain over the drugs-only group was lost at three months, suggesting that the benefits....

Journal, June $1987,150,880$. Letter by Jee. In paragraph 2, "... remitted after a 17-day course of amantidine" should read "... relapsed after ...". 